\title{
GPS Yayın Efemerisi Doğruluğunun İncelenmesi
}

\author{
Sümeyra ERVURAL ${ }^{1 *}$, Ekrem TUŞAT $^{2}$ \\ ${ }^{1}$ Konya Teknik Üniversitesi, Lisansüstü Eğitim Enstitüsü, Harita Mühendisliği Anabilim Dalı, Konya \\ (sumeyraglmz@gmail.com) ORCID ID 0000-0001-7470-3938 \\ ${ }^{2}$ Konya Teknik Üniversitesi, Mühendislik ve Doğa Bilimleri Fakültesi, Harita Mühendisliği Bölümü, Konya \\ (etusat@ktun.edu.tr) ORCID ID 0000-0003-4130-3764
}

\begin{abstract}
Öz
GPS ile konum belirlemede, konum belirleme yöntemine ve hedeflenen doğruluğa bağlı olarak iki farklı yörünge bilgisinden bahsedilebilir. Bunlar; yayın (broadcast) efemerisi ve hassas (precise) efemerisdir. Gerçek zamanlı konum belirlemede yayın efemerisi kullanılmakta olup yaklaşık 1-10 m doğruluğu elde etmek olanaklıdır. Ancak daha yüksek doğruluk beklenen uygulamalar ve özellikle ölçü sonrası büro hesaplamaları ile konum belirleme (statik GPS) için IGS hassas efemeris verileri tercih edilmektedir. Yayın efemeris bilgileri dünyaya dağılmış GPS Kontrol Bölümü izleme istasyonları tarafından yapılan gözlemler yardımıyla üretilmekte ve anlık olarak yayınlanmaktadır. Hassas efemeris verileri ise IGS yörünge bilgilerinden yararlanılarak 24 saat boyunca 30 saniye aralıklarla yapılan gözlemlerin değerlendirilmesiyle oluşmaktadır. Bunun sonucunda haftalık hassas efemerisler yayınlanmaktadır. Bir navigasyon mesajı şeklinde yayınlanan bu efemeris verileri herhangi bir zamanda uydunun anlık konumunun hesaplanabilmesini sağlayan bir Kepler elipsini ifade eder. Bu çalışmada ilk olarak 1 Ocak 2018 tarih 00:00 zamanına ait yayın efemerisi bilgisinden hesaplanan X, Y ve Z koordinatları ile aynı zamana ait IGS sonuç hassas efemeris verisi arasında karşılaştırma yapılarak yayın ve hassas efemeris verilerinin koordinatlar üzerindeki etkisi incelenmiştir. Daha sonra 31 Aralık 2017 tarih 22:00 zamanı ile 1 Ocak 2018 tarih 02:00 zamanı arasında 15 dakika aralıklarla X, Y ve Z koordinatları hesaplanmış ve aynı şekilde hassas efemeris verileriyle farkları alınmıştır. Bu uygulamada seçilen zamanın değiştirilmesiyle elde edilen yayın efemerisi ve hassas efemeris verileri aralarındaki farklar incelenmiş̧ir.
\end{abstract}

Anahtar Kelimeler: GPS, yayın efemerisi, hassas efemeris, Kepler yörünge parametreleri

\section{Analyzing of GPS Broadcast Ephemeris Accuracy}

\begin{abstract}
The GPS positioning, depending on the target location accuracy and detection methods may be mentioned two different orbital information. These are broadcast ephemeris and precise ephemeris. In real-time geodetic applications, generally broadcast ephemeris is used and it is sufficient by providing about 5-10 m accuracy. Precise ephemeris data are preferred for applications with higher accuracy. Publication ephemeris information is produced and instantaneously released by observations made by six GPS Control Departments monitoring stations. Precise ephemeris data are obtained by evaluating the observations made at 30 second intervals for 24 hours using IGS orbital information. As a result, weekly precise ephemeris are published. This ephemeris data, published as a navigation message, refers to a Kepler ellipse that allows the instantaneous location of the satellite to be calculated at any given time. In this study, the $\mathrm{X}, \mathrm{Y}$ and $\mathrm{Z}$ coordinates calculated from the broadcast ephemeris information of the 00:00h of January 1, 2018 and the effects IGS final precise ephemeris data on coordinates were investigated by comparing the ephemeris data of the same time. Then, $\mathrm{X}, \mathrm{Y}$ and $\mathrm{Z}$ coordinates were calculated at $15 \mathrm{~min}$ intervals between 22:00h of 31 December 2017 and 02:00h on January 1,2018 , and the differences were obtained with precise ephemeris data. In this application, the relation
\end{abstract}

* Sorumlu Yazar 
between the broadcast ephemeris and the precise ephemeris data obtained by changing the time chosen was examined.

Keywords: GPS, broadcast ephemeris, precise ephemeris, Kepler orbit parameters.

\section{GİRIȘ}

GNSS sistemleri kullanılarak yüksek doğrulukta konum belirlemek mümkün olabilmektedir. GNSS verilerinin doğruluğu birçok faktöre bağlıdır. Örneğin, GNSS alıcısının özellikleri, verilerin kaydedildiği andaki GNSS uydularının geometrisi, ölçü noktasındaki çevrenin özellikleri ve atmosferik etkiler GNSS verilerinin doğruluğunu etkileyen en önemli faktörlerdir. GPS sistemi, kullanıcılara açılmış ilk GNSS sistemi olmakla birlikte son y1llarda, GLONASS, QZSS, Beidou, Galileo vb. gibi pek çok yeni GNSS sistemi de kullanıcıların hizmetine açılmıştır. Böylece artık kullanıcıların elindeki GNSS alıcılarının özelliklerine (kanal sayısı, jeodezik alıcı, navigasyon alıcı vb.) bağlı olarak tüm bu uydu sistemlerinden gerçek amanlı olarak yararlanmak olanaklı hale gelmiştir.

Uydu jeodezisinde birçok uygulama, zamana bağlı konum belirleyebilmek için belirli bir andaki uydu yörünge elemanları ve bozulmaları kullanarak hesaplanan uydu yörünge bilgisine ihtiyaç duymaktadır. $\mathrm{Bu}$ bilgi yayınlanan navigasyon mesajından elde edilmektedir (Kim ve Kim 2015). Jeodezik uygulamalarda elde edilen sonuçların doğruluğu kullanılan uydu yörünge bilgisinin hassasiyetine bağlıdır. Uydularla Global Konum Belirleme Sistemleri ile bağıl koordinatların belirlenmesi gibi jeodezik uygulamalar için elde edilen doğruluk giderek artmaktadır. Koordinatlarda 1 cm'lik bağıl doğruluk koşulu, uydu yörüngelerinin birkaç metre doğruluk seviyesinde veya daha da iyi olması gerekliliğini ifade eder (Seeber 1993).

Uydu yörüngeleri ve bu yörüngedeki hareketlerini belirlemek için Kepler kanunlarından yararlanılmaktadır. Kepler kanunları; uydunun güneş sistemi içerisinde yaptığı yörünge hareketini açıklamaktadır (Karaali ve Yıldırım 1996). Bu üç hareket kanunu aşağıdaki gibidir:
- Uydu yörüngesi odak noktalarının birinde yerin ağırlık merkezinin bulunduğu bir elipstir.

- Uydunun yer merkezli konum vektörü yörüngede eşit zaman içinde yörünge üzerinde eşit alanı tarar. Bu kanun uydu hızının sabit olmadığını yani uydunun yere en yakın olduğu noktada (perigee) hızlı, yere en uzak olduğu noktada (apogee) yavaş olduğunu göstermektedir.

- Uydunun yörüngesel dönmesini tamamladığı $\mathrm{P}$ süresinin karesi, yörünge elipsinin büyük yarı ekseni olan a'nın küpü ile doğru orantılı ve sabittir (Formül 1).

$$
\frac{P^{2}}{a^{3}}=\frac{4 \pi^{2}}{\mu}
$$

Burada $\mu=\mathrm{GM}$ olup, $\mathrm{G}$, uluslararas1 gravite sabiti, $M$, dünyanın kütlesidir.

Bir uydunun Kepler hareketinin veya yörüngesinin bulunması ve uydunun bu yörünge üzerindeki konumunun belirlenmesi için, uydu yörüngesine ait 6 tane parametreye ihtiyaç vardır. Bunlar Şekil 1 ve Tablo 1'de gösterilmiştir.

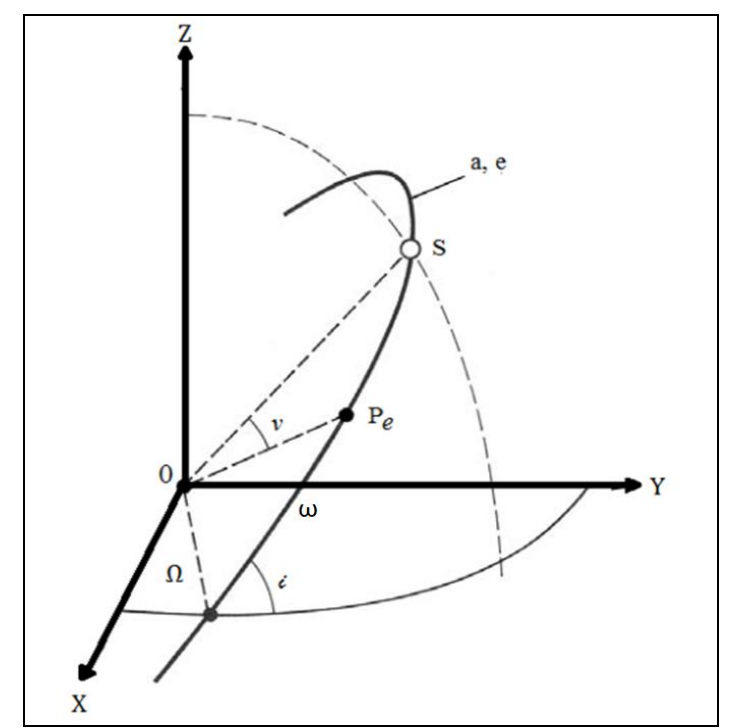

Şekil 1. Kepler Yörünge Elemanları (Seeber 1993)

Kepler yörünge elemanlarından yarı ana eksen (a) yörüngenin boyutunu ve dış merkezlik (e) 
yörüngenin şeklini belirtir. Yerberi (Perigee) argümanı $(\omega)$ ise yörüngenin yönünü belirtir. Yani yükselen düğüm ile Yerberi arasındaki açı uydunun hareket yönünü gösterir (İpek 2017).

Tablo 1. Kepler Yörünge Parametreleri

\begin{tabular}{|c|c|}
\hline Parametre & Açıklama \\
\hline$\Omega$ & $\begin{array}{l}\text { Düğüm noktasının ilkbahar noktasından } \\
\text { itibaren gök ekvator düzleminde yaptığı açı }\end{array}$ \\
\hline $\mathrm{i}$ & $\begin{array}{c}\text { Ekvator düzlemi ile uydu yörüngesi } \\
\text { arasındaki açı }\end{array}$ \\
\hline$\omega$ & Yerberi (Perigee) noktasının argümanı \\
\hline $\mathrm{a}$ & Yörünge elipsinin büyük yarı ekseni \\
\hline $\mathrm{e}$ & Dış merkezlik (Eksantrisite) \\
\hline $\mathrm{Pe}$ & $\begin{array}{l}\text { Yerberi (Perigee) den uydunun geçiş } \\
\text { zamanı }\end{array}$ \\
\hline
\end{tabular}

\section{GPS UYDU YÖRÜNGELERİ (EFEMERISLER)}

Efemeris verileri herhangi bir zamanda uydunun anlik konumunun hesaplanmasinı sağlayan bir Kepler elipsini ifade eder (Parkinson ve Spilker, 1996). İki tür efemeristen söz edilebilir.

Yayın efemerisleri bir navigasyon mesaj1 şeklinde yayınlanmakta olup anlık konum belirleme uygulamalarında kullanılmaktadır. Hassas efemeris ise daha çok GPS verilerinin ölçü sonrası büroda değerlendirilme aşamasında kullanılmaktadır (Tuşat ve Turgut 2004). GPS ile elde edilen verilerdeki noktaların konum doğruluğu efemeris bilgilerinin doğruluğu ile orantılıdır.

Günümüzde bilimsel çalışmalarda ve mühendislik uygulamalarında kullanılabilecek GPS ölçümlerinin toplanması, arşivlenmesi ve dağıtılmasından Jeodinamik için Uluslararası GPS Servisi (IGS) sorumludur. Yayın ve NGS hassas efemerislerinin aksine IGS hassas efemeris yörünge bilgileri, duyarl1 P-Kod alıcılarının kurulu olduğu global ağda yapılan faz gözlemlerinden elde edilmektedir. IGS yörünge doğrulukları Tablo 2'de gösterilmiştir.
Tablo 2. IGS Yörünge Doğrulukları (IGS, 2019)

\begin{tabular}{|c|c|c|}
\hline Yörünge & Doğruluk & $\begin{array}{l}\text { Elde Etme } \\
\text { Süresi }\end{array}$ \\
\hline $\begin{array}{c}\text { Yayın Efemerisi } \\
\text { (Broadcast) }\end{array}$ & $\sim 100 \mathrm{~cm} / 5 \mathrm{~ns}$ & Anlik \\
\hline $\begin{array}{l}\text { IGS Kestirim } \\
\text { (predicted) }\end{array}$ & $\sim 5 \mathrm{~cm} / 3 \mathrm{~ns}$ & Anlık \\
\hline $\begin{array}{l}\text { IGS Kestirim } \\
\text { (observed) }\end{array}$ & $\sim 3 \mathrm{~cm} / 150 \mathrm{ps}$ & $3-9$ saat \\
\hline $\begin{array}{l}\text { IGS Hizlı } \\
\text { (Rapid) }\end{array}$ & $2.5 \mathrm{~cm} / 75 \mathrm{ps}$ & $17-41$ saat \\
\hline $\begin{array}{l}\text { IGS Sonuç } \\
\text { (Final) }\end{array}$ & $<2.5 \mathrm{~cm} / 20 \mathrm{ps}$ & 1-18 gün \\
\hline
\end{tabular}

\subsection{Yaym Efemerisi}

Yayın efemerisleri yeryüzüne dağılmış altı GPS Kontrol Bölümü izleme istasyonlan tarafından yapılan gözlemler yardımıyla üretilmektedir. Ana kontrol istasyonu düzeltilmiş bilgileri uydulara yükler ve GPS uyduları tarafindan kullanıcıya "yayın" olarak iletilir. Yayın bilgisine GPS navigasyon mesaj1 dosyası olarak ulaşılabilmekte olup, her bir uydu için koordinatları ve saat düzeltmesini hesaplamak üzere gerekli Kepler parametrelerini verir. $\mathrm{Bu}$ efemeris verileri ayn zamanda uydunun saatini GPS saati ile eşleştirmek için gereken süreyi de içerir. Uydu saatindeki hata ve yörünge parametreleri hatalı yörünge kestirme hesabıyla sonuçlanır (Bidikar vd. 2014).

Yayın efemerisleri ölçme sonrası değerlendirmede de kullanılabildiği gibi genellikle gerçek zamanlı uygulamalarda kullanılır. Bu efemeris ile elde edilen uydu koordinat doğrulukları yaklaşık $\pm 5 \mathrm{~m}$ civarında olup birçok jeodezik uygulamada yeterli doğruluğu vermektedir (Seeber 1993). Fakat çözümünde kullanılan ekstrapolasyondan dolayı yüksek duyarlılık gerektiren uygulamalar için yeterli olmamaktadır (Xu 2016).

\subsection{Hassas Efemeris}

Hassas efemeris, dünya genelinde dağılmış çok sayıda istasyondan gelen uydu verilerini değerlendirerek elde edilir. İnternet üzerinden ücretsiz olarak kullanıcıya sunulmaktadır. Hassas efemeris bilgilerini üreten kurum ve kuruluşlardan en çok bilinenleri Tablo 3 'te gösterilmiştir. Bunların dışında hassas yörünge bilgisi üreten çok sayıda kurum ve kuruluş bulunmaktadır. 
Tablo 3. Hassas Yörünge ve Saat Bilgileri Üreten Kurum ve Kuruluşlardan Bazıları (Kahveci ve Y1ldız 2009)

\begin{tabular}{ll}
\hline \multicolumn{1}{c}{ Kurum/ Kuruluş Ad 1} & $\begin{array}{c}\text { Kullanılan } \\
\text { Yazılım }\end{array}$ \\
\hline Jet Propulsion Laboratory (JPL) & $\begin{array}{l}\text { GIPSY- } \\
\text { OASIS II }\end{array}$ \\
$\begin{array}{l}\text { Scripps Orbit and Permanent Array } \\
\text { Center (SOPAC) }\end{array}$ & GAMIT \\
$\begin{array}{l}\text { Center for Orbit Determination in Europe } \\
\text { (CODE) }\end{array}$ & BERNESE \\
National Geodetic Survey (NGS) & PAGE5 \\
\hline
\end{tabular}

Efemeris dosyalarında her uydu için 15 dakika aralıklarla $\mathrm{km}$ cinsinde $\mathrm{X}, \mathrm{Y}, \mathrm{Z}$ konum vektörleri ve ilgili saat hataları yer almaktadır. $\mathrm{Bu}$ veri dosyaları kullanılarak enterpolasyon yöntemiyle istenilen herhangi bir zaman için yörünge hesabı yapılabilir (Xu 2016).

Hassas efemerislerin doğruluğu yaklaşık birkaç santimetre seviyesindedir (IGS 2019). Günümüzde halen kullanılmakta olan birçok jeodezik kontrol noktası, nokta konumlandırma teknikleri ve hassas efemerisler ile belirlenmiştir (Seeber 1993).

\section{YÖNTEM}

$\mathrm{Bu}$ çalışmada koordinatların belirlenmesinde efemeris bilgisinin etkileri incelenmiştir. Uygulamada 1 Ocak 2018 tarih ve 00:00 zamanına ait hassas (igs19821.sp3) efemeris (IGS sonuç) ve yayın (brdc0010.18n) efemerisi ile 31 Aralı 2017 tarihine ait hassas (igs19820.sp3) efemeris bilgileri kullanılmıştır. Efemeris verileri ile ECEF koordinat sisteminde koordinatlar hesaplanmış ve elde edilen sonuçlar karşılaştırılmıştır. ECEF koordinat sisteminde bir GPS uydu yörüngesini hesaplamak için kullanılan RINEX navigasyon dosyasının 1 numaralı uyduya ait veri bloğu Şekil 2' de verilirken hesaplama için kullanılacak olan algoritmalar Tablo 4'de gösterilmiştir.

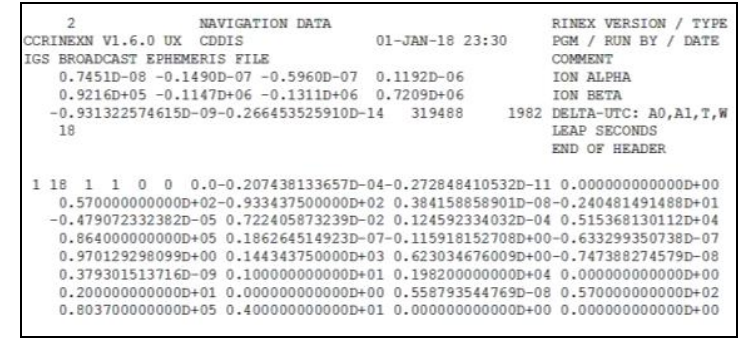

Şekil 2. 1 Numaralı Uydu için RINEX Veri Bloğu

Tablo 4. Uydu Konum Hesab1 Algoritmas1

\begin{tabular}{|c|c|}
\hline Parametre & Eşitlik \\
\hline $\begin{array}{l}\text { Yerçekim } \\
\text { sabiti }\end{array}$ & $G M_{e}=3986004418.10^{8} \mathrm{~m}^{3} / \mathrm{s}^{2}($ WGS 84$)$ \\
\hline $\begin{array}{l}\text { Yerin açısal } \\
\text { dönme hızı }\end{array}$ & $W_{e}=7.2921151467 .10^{-5} \mathrm{rad} / \mathrm{s}($ WGSS4 $)$ \\
\hline $\begin{array}{l}\text { Yörünge } \\
\text { büyük yarı } \\
\text { ekseni }\end{array}$ & $a=(\sqrt{a})^{2}$ \\
\hline $\begin{array}{l}\text { Ortalama } \\
\text { yörünge hız1 }\end{array}$ & $n_{0}=\sqrt{\frac{G M}{a^{3}}}$ \\
\hline $\begin{array}{l}\text { Düzeltilmiş } \\
\text { yörünge hızı }\end{array}$ & $n=n_{0}+\Delta n$ \\
\hline $\begin{array}{l}\text { toe'ye göre } \\
\text { zaman }\end{array}$ & $t_{k}=t-t_{0 e}$ \\
\hline $\begin{array}{l}\text { Ortalama } \\
\text { anomali }\end{array}$ & $M_{k}=M_{0}+n \cdot t_{k}$ \\
\hline $\begin{array}{l}\text { Diş merkez } \\
\text { anomali }\end{array}$ & $E_{k}=M_{k}-e \cdot \operatorname{Sin} E_{k}$ \\
\hline $\begin{array}{l}\text { Gerçek } \\
\text { anomali }\end{array}$ & $v_{k}=\tan ^{-1}\left(\frac{\sqrt{1-e^{2}} \cdot \operatorname{Sin} E_{k}}{\cos E_{k}-e}\right)=\operatorname{Cos}^{-1}\left(\frac{\operatorname{Cos} E_{k}-e}{1-e \cdot \cos E_{k}}\right.$ \\
\hline $\begin{array}{c}\text { Enlem } \\
\text { argümanı }\end{array}$ & $U_{k}=\omega+V_{k}$ \\
\hline $\begin{array}{c}\text { Enlem } \\
\text { argümanı } \\
\text { düzeltmesi }\end{array}$ & $\delta U_{k}=C_{u c} \cdot \cos 2 U_{k}+C_{u s} \cdot \sin 2 U_{k}$ \\
\hline $\begin{array}{l}\text { Yarıçap } \\
\text { düzeltmesi }\end{array}$ & $\delta r_{k}=C_{r c} \cdot \cos 2 U_{k}+C_{r s} \sin 2 U_{k}$ \\
\hline
\end{tabular}




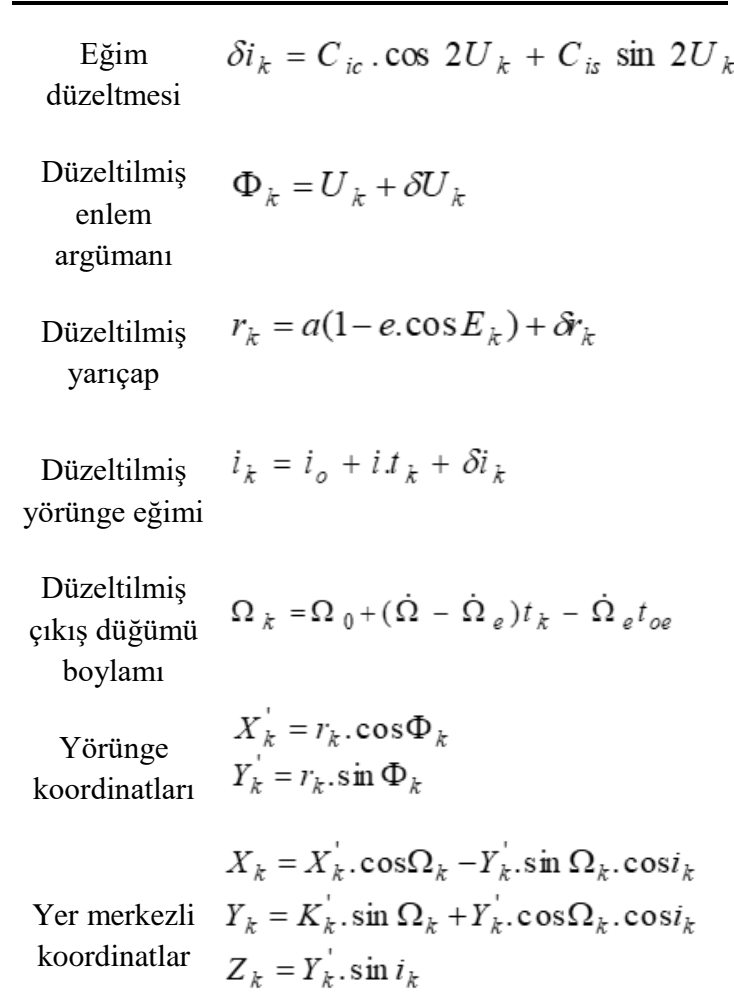

İlk olarak 1 Ocak 2018 tarih ve 00:00 zamanına ait yayınlanan yörünge verileri kullanılarak bütün uydular için ECEF koordinat sistemindeki $\mathrm{X}, \mathrm{Y}$ ve $\mathrm{Z}$ koordinatları hesaplanmış ve aynı zamana ait hassas efemerislerle farkı alınmıştır. Böylece yayın ve IGS hassas efemerisin koordinatlar üzerindeki etkisi gözlenmiştir.

Daha sonra yayın efemeris verileri kullanılarak seçilen 1 Ocak 2018 tarih ve 00:00 zamanında 15 dakikalık öteleme hesapları yapılmıştır. 31 Aralık 2017 tarih 22:00 zamanı ve 1 Ocak 2018 tarih 02:00 zamanı arasında bütün uydular için 15 dakika aralıklarla ECEF koordinat sistemindeki X, Y, Z koordinatları hesaplanarak aynı şekilde hassas efemeris verileriyle karşılaştırılmıştır. Elde edilen sonuçlar üzerinde her zaman diliminde en yüksek ve en düşük değer, ortalama değer ve standart sapma değerleri hesaplanmıştır. Bu uygulamada seçilen zamanın değiştirilmesiyle elde edilen yayin ve hassas efemeris verileri arasındaki ilişki incelenmiştir.

\section{BULGULAR}

1 Ocak 2018 tarih ve 00:00 saati için yayınlanan verilerden hesaplanan ECEF koordinat sistemindeki $\mathrm{X}, \mathrm{Y}$ ve $\mathrm{Z}$ koordinatlar1 ile aynı zamana ait hassas efemeris verileri ve bu verinin karşılaştırıldığı çizelgeler Tablo 5, Tablo 6, Tablo 7 ve Tablo 8'de verilmiştir.

Tablo 5. Yayin Efemerisi Verilerinden Hesaplanan Koordinatlar

YAYIN EFEMERISII

$\begin{array}{llllll}18 & 1 & 1 & 0 & 0 & 00: 00\end{array}$

\begin{tabular}{|c|c|c|c|}
\hline SV & $\mathrm{X}(\mathrm{m})$ & $\mathrm{Y}(\mathrm{m})$ & $\mathrm{Z}(\mathrm{m})$ \\
\hline PG01/1 & -7746387.7902 & -13820659.3845 & -21494942.4716 \\
\hline $\mathrm{PG} 02 / 2$ & -16146095.7934 & 14527213.7790 & 15627540.0631 \\
\hline PG03/3 & -12362480.8175 & -22753025.5019 & -6038320.6393 \\
\hline PG05/5 & -4900809.9500 & 16694000.4726 & 19909026.5437 \\
\hline PG06/6 & -24712779.6785 & 7688502.1966 & 6021510.6784 \\
\hline PG07/7 & -22163680.3846 & -6866636.3715 & 13521019.9381 \\
\hline PG08/8 & 4333532.8797 & -25046337.1296 & -7426493.4808 \\
\hline PG09/9 & -12036085.1535 & -10539771.4526 & 21163355.2617 \\
\hline PG10/10 & 19069679.6251 & 3749340.5944 & -18140980.2745 \\
\hline PG11/11 & -3534266.8310 & -16963021.6099 & -20714962.0147 \\
\hline PG12/12 & 9185358.6275 & 23532040.3514 & -8696332.2425 \\
\hline PG13/13 & -12056095.1235 & 23649241.5880 & -1219772.0412 \\
\hline PG14/14 & 17484432.5449 & -14927326.4443 & -12876711.2420 \\
\hline PG15/15 & -999757.4085 & 24916629.6580 & -8766109.0732 \\
\hline PG16/16 & 5256643.2264 & -16163001.0183 & 20153073.9072 \\
\hline PG17/17 & -16954250.2487 & 6398054.5045 & -18984750.5905 \\
\hline PG18/18 & 20772760.2425 & 13717704.4358 & -8894617.7929 \\
\hline PG19/19 & -18042461.5743 & 13563900.0964 & -14444622.3032 \\
\hline PG20/20 & 12034092.4904 & 21965766.3276 & 8752969.0682 \\
\hline PG22/22 & -7161011.4258 & -22314072.2408 & -12240051.0192 \\
\hline PG23/23 & -4762876.1044 & -20376873.2103 & 16364016.0608 \\
\hline PG24/24 & 4650222.6738 & 15020451.8549 & -21522336.9964 \\
\hline PG25/25 & 17827033.3187 & 19590600.6024 & 3092182.3060 \\
\hline PG26/26 & 13438898.8081 & -7595925.3116 & 21623966.4478 \\
\hline PG27/27 & 12421154.0722 & -22889476.8879 & 4466444.9541 \\
\hline PG28/28 & -18544560.5789 & -8914616.1350 & -16141433.5266 \\
\hline PG29/29 & 7867522.2095 & 15087399.5113 & 20389820.6573 \\
\hline PG30/30 & -26181661.7740 & -1244744.4498 & 4754123.1813 \\
\hline PG31/31 & 24737691.3380 & -7541964.7174 & 6996503.0608 \\
\hline PG32/32 & 17216801.8621 & -7995767.1809 & -18526452.1300 \\
\hline
\end{tabular}


Tablo 6. Hassas Efemeris Dosyasından Alınan Koordinatlar

HASSAS EFEMERİS (PG)

$\begin{array}{llllll}18 & 1 & 1 & 0 & 0 & 00: 00\end{array}$

\begin{tabular}{|c|c|c|c|}
\hline SV & $\mathrm{X}(\mathrm{m})$ & $\mathrm{Y}(\mathrm{m})$ & $\mathrm{Z}(\mathrm{m})$ \\
\hline PG01/1 & -7746389.210 & -13820659.479 & -21494943.319 \\
\hline PG02/2 & -16146095.026 & 14527214.173 & 15627540.391 \\
\hline PG03/3 & -12362480.870 & -22753026.810 & -6038321.404 \\
\hline PG05/5 & -4900810.713 & 16693999.959 & 19909026.570 \\
\hline PG06/6 & -24712780.585 & 7688503.452 & 6021512.570 \\
\hline PG07/7 & -22163680.755 & -68666636.968 & 13521019.272 \\
\hline PG08/8 & 4333533.776 & -25046338.006 & -7426494.909 \\
\hline PG09/9 & -12036085.259 & -10539771.655 & 21163356.509 \\
\hline PG10/10 & 19069680.003 & 3749341.392 & -18140981.202 \\
\hline PG11/11 & -3534268.730 & -16963022.391 & -20714963.195 \\
\hline PG12/12 & 9185357.848 & 23532040.166 & -8696332.711 \\
\hline PG13/13 & -12056096.069 & 23649242.912 & -1219772.260 \\
\hline PG14/14 & 17484433.477 & -14927327.815 & -12876711.732 \\
\hline PG15/15 & -999757.486 & 24916629.494 & -8766109.619 \\
\hline PG16/16 & 5256644.115 & -16163001.999 & 20153075.239 \\
\hline PG17/17 & -16954250.928 & 6398056.130 & -18984749.562 \\
\hline PG18/18 & 20772761.087 & 13717705.750 & -8894618.323 \\
\hline PG19/19 & -18042461.985 & 13563899.127 & -14444622.602 \\
\hline PG20/20 & 12034093.628 & 21965767.793 & 8752968.685 \\
\hline PG22/22 & -7161012.283 & -22314072.663 & -12240050.279 \\
\hline $\mathrm{PG} 23 / 23$ & -4762877.326 & -20376871.632 & 16364017.964 \\
\hline PG24/24 & 4650223.399 & 15020452.529 & -21522337.630 \\
\hline PG25/25 & 17827033.275 & 19590602.218 & 3092181.529 \\
\hline PG26/26 & 13438899.779 & -7595926.227 & 21623966.592 \\
\hline PG27/27 & 12421154.886 & -22889477.768 & 4466444.145 \\
\hline PG28/28 & -18544561.327 & -8914617.585 & -16141434.218 \\
\hline PG29/29 & 7867521.185 & 15087399.631 & 20389820.773 \\
\hline PG30/30 & -26181663.067 & -1244744.301 & 4754122.711 \\
\hline PG31/31 & 24737691.381 & -7541964.340 & 6996502.646 \\
\hline PG32/32 & 17216802.573 & -7995768.161 & -18526452.608 \\
\hline
\end{tabular}

Tablo 7. Yayın ve Hassas Efemeris Verilerinden Elde Edilen Koordinatlar Arasındaki Farklar

\begin{tabular}{|c|c|c|c|}
\hline \multicolumn{4}{|c|}{ FARKLAR } \\
\hline SV & $\mathrm{X}(\mathrm{m})$ & $\mathrm{Y}(\mathrm{m})$ & $\mathrm{Z}(\mathrm{m})$ \\
\hline PG01/1 & -1.4197 & -0.0945 & -0.8473 \\
\hline $\mathrm{PG} 02 / 2$ & 0.7674 & 0.3939 & 0.3278 \\
\hline PG03/3 & -0.0524 & -1.3080 & -0.7646 \\
\hline PG05/5 & -0.7629 & -0.5136 & 0.0262 \\
\hline PG06/6 & -0.9064 & 1.2553 & 1.8915 \\
\hline PG07/7 & -0.3703 & -0.5964 & -0.6661 \\
\hline PG08/8 & 0.8962 & -0.8763 & -1.4281 \\
\hline PG09/9 & -0.1054 & -0.2023 & 1.2472 \\
\hline PG10/10 & 0.3778 & 0.7975 & -0.9274 \\
\hline PG11/11 & -1.8989 & -0.7810 & -1.1802 \\
\hline PG12/12 & -0.7795 & -0.1854 & -0.4684 \\
\hline PG13/13 & -0.9454 & 1.3239 & -0.2187 \\
\hline PG14/14 & 0.9320 & -1.3706 & -0.4899 \\
\hline PG15/15 & -0.0774 & -0.1640 & -0.5457 \\
\hline PG16/16 & 0.8885 & -0.9806 & 1.3317 \\
\hline PG17/17 & -0.6792 & 1.6254 & 1.0285 \\
\hline PG18/18 & 0.8444 & 1.3141 & -0.5300 \\
\hline PG19/19 & -0.4106 & -0.9694 & -0.2987 \\
\hline PG20/20 & 1.1375 & 1.4653 & -0.3832 \\
\hline PG22/22 & -0.8571 & -0.4221 & 0.7402 \\
\hline PG23/23 & -1.2215 & 1.5783 & 1.9031 \\
\hline PG24/24 & 0.7251 & 0.6740 & -0.6335 \\
\hline PG25/25 & -0.0437 & 1.6155 & -0.7770 \\
\hline PG26/26 & 0.9708 & -0.9153 & 0.1441 \\
\hline G27/27 & 0.8137 & -0.8800 & -0.8091 \\
\hline PG28/28 & -0.7480 & -1.4499 & -0.6913 \\
\hline PG29/29 & -1.0245 & 0.1196 & 0.1156 \\
\hline PG30/30 & -1.2929 & 0.1488 & -0.4703 \\
\hline PG31/31 & 0.0429 & 0.3774 & -0.4148 \\
\hline PG32/32 & 0.7108 & -0.9800 & -0.4779 \\
\hline
\end{tabular}


Tablo 8. Yayın ve Hassas Efemeris Verilerinden Elde Edilen Koordinatlar Arasındaki Farkların Ortalama, En Büyük, En Küçük ve Standart Sapma Değerleri

\begin{tabular}{lrrr}
\hline & $\mathrm{X}(\mathrm{m})$ & $\mathrm{Y}(\mathrm{m})$ & $\mathrm{Z}(\mathrm{m})$ \\
\hline ORTALAMA & -0.1496 & -0.0000 & -0.1422 \\
EN KÜÇÜK & -1.8989 & -1.4499 & -1.4281 \\
EN BÜYÜK & 1.1375 & 1.6254 & 1.9031 \\
STD. SAPMA & 0.8707 & 0.9969 & 0.8668 \\
\hline
\end{tabular}

$\mathrm{Bu}$ tablolar incelendiğinde farkların $\mathrm{X}$ ekseninde $-1.9 \mathrm{~m}$ ile $+1.1 \mathrm{~m}$, Y ekseninde -1.5 $\mathrm{m}$ ile $+1.6 \mathrm{~m}, \mathrm{Z}$ ekseninde $-1.4 \mathrm{~m}$ ile $+1.9 \mathrm{~m}$ değerleri arasında olduğu görülmektedir. Tabloda yer alan farkların ortalama değerleri $\mathrm{X}$ koordinat bileşeni için $\sim-15 \mathrm{~cm}$, Y koordinat bileşeni için $\sim 0 \mathrm{~cm}, \mathrm{Z}$ koordinat bileşeni için $-14 \mathrm{~cm}$ olup, standart saplamaları ise $\mathrm{X}$ koordinat bileşeni için $0.9 \mathrm{~m}, \mathrm{Y}$ koordinat bileşeni için $1 \mathrm{~m}, \mathrm{Z}$ koordinat bileşeni için 0.9 $\mathrm{m}$ olarak hesaplanmıştır. Ayrıca yayın efemerisi yörünge verileri kullanılarak 31 Aralık 2017 tarihi 22:00 zamanı ve 1 Ocak 2018 tarihi 00:00 zamanı arasında bütün uydular için $\mathrm{t}$ değeri değiştirilerek 15 dakikalık zaman farklarında $\mathrm{X}, \mathrm{Y}$ ve $\mathrm{Z}$ değerleri elde edilmiştir. Bulunan bu değerler yine hassas efemeris değerleriyle karşılaştırılmıştır. Karşılaştırılma sonuçları Tablo 9 ve Tablo 10 'da verilmiştir.

Tablo 9. Yayın Efemerisi ve Hassas Efemeris Arasındaki Farkların Minimum, Maksimum, Ortalama ve Standart Sapma Değerleri (22:0000:00 aras1)

\begin{tabular}{lllll}
\hline \multirow{2}{*}{2200.00} & & \multicolumn{1}{c}{$\mathrm{x}$} & \multicolumn{1}{c}{$\mathrm{y}$} & \multicolumn{1}{c}{$\mathrm{z}$} \\
\cline { 2 - 5 } & Minimum(m) & -3.265 & -2.251 & -2.769 \\
& Maksimum(m) & 2.907 & 3.435 & 3.482 \\
& Ortalama(m) & 0.018 & 0.020 & 0.090 \\
& Std Sapma(m) & 1.585 & 1.467 & 1.779 \\
\hline 22150.00 & Minimum(m) & -3.681 & -2.267 & -2.646 \\
& Maksimum(m) & 2.119 & 2.607 & 3.043 \\
& Ortalama(m) & -0.086 & -0.040 & 0.017 \\
& Std Sapma(m) & 1.374 & 1.280 & 1.592 \\
\hline 22300.00 & Minimum(m) & -3.810 & -2.329 & -2.739 \\
& Maksimum(m) & 1.653 & 2.139 & 2.653 \\
& Ortalama(m) & -0.138 & -0.066 & -0.036 \\
& Std Sapma(m) & 1.246 & 1.173 & 1.469 \\
\hline 22450.00 & Minimum(m) & -3.720 & -2.278 & -2.729 \\
& Maksimum(m) & 1.497 & 1.959 & 2.590 \\
& Ortalama(m) & -0.159 & -0.072 & -0.074 \\
\hline
\end{tabular}

\begin{tabular}{lllll}
\hline & Std Sapma(m) & 1.142 & 1.089 & 1.351 \\
\hline 2300.00 & Minimum(m) & -3.468 & -2.087 & -2.641 \\
& Maksimum(m) & 1.433 & 1.868 & 2.555 \\
& Ortalama(m) & -0.163 & -0.065 & -0.101 \\
& Std Sapma(m) & 1.057 & 1.022 & 1.227 \\
\hline 23150.00 & Minimum(m) & -3.110 & -1.820 & -2.373 \\
& Maksimum(m) & 1.406 & 1.869 & 2.420 \\
& Ortalama(m) & -0.161 & -0.050 & -0.119 \\
& Std Sapma(m) & 0.994 & 0.984 & 1.108 \\
\hline 23300.00 & Minimum(m) & -2.695 & -1.580 & -2.019 \\
& Maksimum(m) & 1.373 & 1.852 & 2.239 \\
& Ortalama(m) & -0.157 & -0.033 & -0.130 \\
& Std Sapma(m) & 0.949 & 0.977 & 1.003 \\
\hline 23450.00 & Minimum(m) & -2.268 & -1.515 & -1.677 \\
& Maksimum(m) & 1.289 & 1.765 & 2.055 \\
& Ortalama(m) & -0.152 & -0.016 & -0.136 \\
& Std Sapma(m) & 0.907 & 0.987 & 0.920 \\
\hline
\end{tabular}

Tablo 10. Yayın Efemerisi ve Hassas Efemeris Arasındaki Farkların Minimum, Maksimum, Ortalama ve Standart Sapma Değerleri (00:00 $-02: 00$ aras1)

\begin{tabular}{|c|c|c|c|c|}
\hline \multirow{5}{*}{000.00} & & $\mathrm{x}$ & $\mathrm{y}$ & $\mathrm{z}$ \\
\hline & $\operatorname{Minimum}(\mathrm{m})$ & -1.899 & -1.450 & -1.428 \\
\hline & $\operatorname{Maksimum}(\mathrm{m})$ & 1.138 & 1.625 & 1.903 \\
\hline & Ortalama(m) & -0.150 & 0.000 & -0.142 \\
\hline & Std Sapma(m) & 0.871 & 0.997 & 0.867 \\
\hline \multirow[t]{4}{*}{0150.00} & $\operatorname{Minimum}(\mathrm{m})$ & -1.572 & -1.627 & -1.380 \\
\hline & Maksimum(m) & 1.080 & 1.656 & 1.923 \\
\hline & Ortalama(m) & -0.147 & 0.008 & -0.147 \\
\hline & Std Sapma(m) & 0.841 & 0.992 & 0.853 \\
\hline \multirow[t]{4}{*}{0300.00} & $\operatorname{Minimum}(\mathrm{m})$ & -1.551 & -1.733 & -1.507 \\
\hline & Maksimum(m) & 1.177 & 1.660 & 1.788 \\
\hline & Ortalama(m) & -0.146 & 0.013 & -0.154 \\
\hline & Std Sapma(m) & 0.852 & 0.985 & 0.882 \\
\hline \multirow[t]{4}{*}{0450.00} & $\operatorname{Minimum}(\mathrm{m})$ & -1.835 & -1.811 & -1.659 \\
\hline & Maksimum(m) & 1.273 & 1.701 & 1.515 \\
\hline & Ortalama(m) & -0.146 & 0.016 & -0.164 \\
\hline & Std Sapma(m) & 0.920 & 0.994 & 0.942 \\
\hline \multirow[t]{4}{*}{100.00} & $\operatorname{Minimum}(\mathrm{m})$ & -2.086 & -1.905 & -1.945 \\
\hline & $\operatorname{Maksimum}(\mathrm{m})$ & 1.387 & 1.938 & 1.254 \\
\hline & Ortalama(m) & -0.145 & 0.021 & -0.172 \\
\hline & Std Sapma(m) & 1.036 & 1.034 & 1.013 \\
\hline \multirow[t]{3}{*}{1150.00} & $\operatorname{Minimum}(\mathrm{m})$ & -2.270 & -2.050 & -2.163 \\
\hline & $\operatorname{Maksimum(m)}$ & 1.726 & 2.125 & 1.397 \\
\hline & Ortalama(m) & -0.138 & 0.030 & -0.171 \\
\hline
\end{tabular}




\begin{tabular}{|c|c|c|c|c|}
\hline & $\operatorname{Std} \operatorname{Sapma}(\mathrm{m})$ & 1.169 & 1.102 & 1.075 \\
\hline \multirow[t]{4}{*}{1300.00} & $\operatorname{Minimum}(\mathrm{m})$ & -2.353 & -2.147 & -2.272 \\
\hline & $\operatorname{Maksimum(m)}$ & 2.058 & 2.246 & 1.488 \\
\hline & Ortalama(m) & -0.119 & 0.043 & -0.148 \\
\hline & Std Sapma(m) & 1.292 & 1.180 & 1.116 \\
\hline \multirow[t]{4}{*}{1450.00} & $\operatorname{Minimum}(\mathrm{m})$ & -2.509 & -2.280 & -2.250 \\
\hline & Maksimum(m) & 2.312 & 2.277 & 1.973 \\
\hline & Ortalama(m) & -0.081 & 0.057 & -0.090 \\
\hline & Std Sapma(m) & 1.405 & 1.253 & 1.161 \\
\hline \multirow[t]{4}{*}{200.00} & $\operatorname{Minimum}(\mathrm{m})$ & -2.885 & -2.991 & -2.103 \\
\hline & $\operatorname{Maksimum}(\mathrm{m})$ & 2.714 & 2.186 & 2.748 \\
\hline & Ortalama(m) & -0.021 & 0.061 & 0.019 \\
\hline & $\operatorname{Std} \operatorname{Sapma}(\mathrm{m})$ & 1.556 & 1.335 & 1.302 \\
\hline
\end{tabular}

Tablo 9 ve Tablo 10'da ifade edilen yayın ve hassas efemeris arasındaki farklara göre X, Y ve $Z$ değerleri için minimum ve maksimum değerleri düzensiz dağılım gösterirken, bütün uydular için alınan ortalama değerlerin her üç bileşen içinde sıfıra yakın değerlerde olduğu gözlenmiştir. Hesaplamalarda 1 Ocak 2018 ve 00:00 zamanı referans kabul edildiğinde değiştirilen $t$ değerinin pozitif olduğu durumlarda yayın ve hassas efemeris arasındaki farkın 3 m'nin altında olduğu görülürken, $\mathrm{t}$ değerinin negatif alınarak kullanıldığ 1 durumlarda ise bu fark $3.8 \mathrm{~m}^{\text {'ye }}$ yaklaşmıştır. 3 m'nin üstünde çıkan farkların en çok X bileşeninde olduğu ve zaman değişse bile belirli uydularda bu durumun tekrarlandığ sonucuna varılmıştır.

Tablolarda ifade edilen $X, Y$ ve $Z$ koordinatlarındaki farklara ilişkin minimum, maksimum, ortalama ve standart sapma değerleri zaman ekseninde grafik şekline dönüştürülmüş olup Şekil 3, Şekil 4 ve Şekil 5 'de gösterilmiştir.

Aşağıdaki verilmiş olan grafiklerde görülen bir diğer bileşen olarak hesaplanan standart sapma ise $\mathrm{X}, \mathrm{Y}$ ve $\mathrm{Z}$ bileşenlerinde yaklaşık benzer eğriyi oluşturduğu ve sifır anından uzaklaştıkça standart sapma değerinin arttı̆̆ sonucuna varılmıştır. Üç bileşen içinde 00:00 zamanında minimum değerlerde olan standart sapmalar X bileşeni için $1.6 \mathrm{~m}$, Y bileşeni için $1.5 \mathrm{~m}, \mathrm{Z}$ bileşeni için $1.8 \mathrm{~m}$ en yüksek değerlerini almıştır.

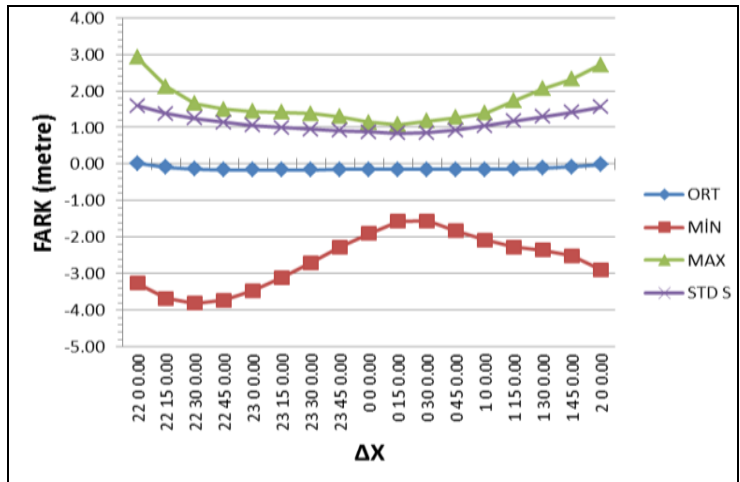

Şekil 3. Hassas Efemeris ve Yayın Efemeris Verilerinden elde edilen X Koordinatı Fark Değerleri

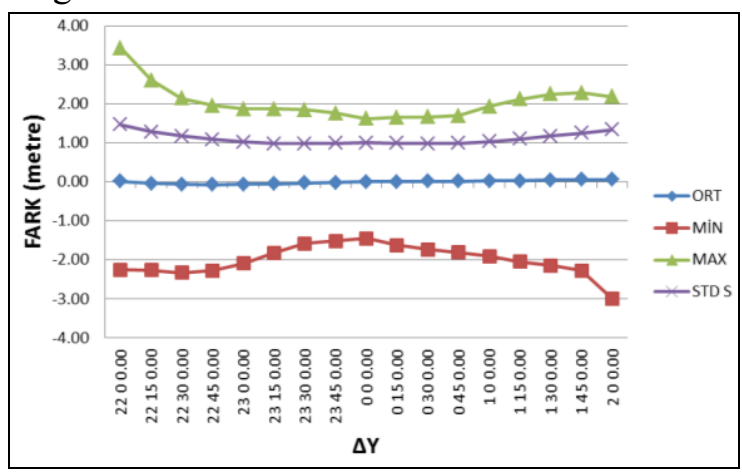

Şekil 4. Hassas Efemeris ve Yayın Efemeris Verilerinden elde edilen Y Koordinat1 Fark Değerleri

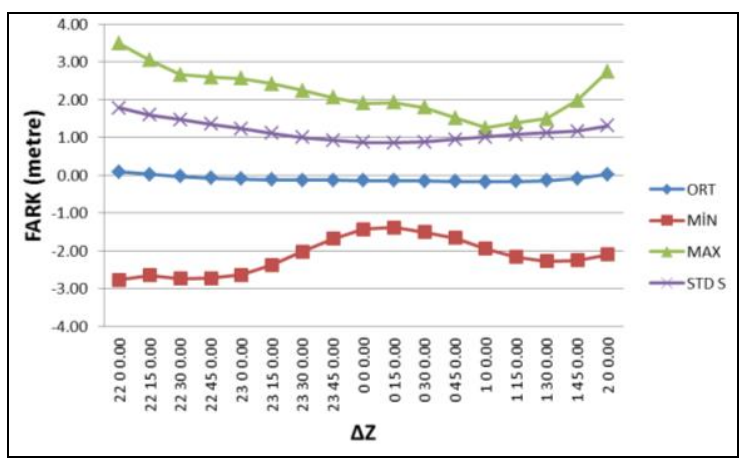

Şekil 5. Hassas Efemeris ve Yayın Efemeris Verilerinden elde edilen Z Koordinat1 Fark Değerleri

\section{SONUÇLAR VE TARTIŞMA}

$\mathrm{Bu}$ çalışmada yayın ve hassas efemeris verileri ile elde edilen koordinatlar zamana bağlı olarak karşılaştırılmıştır. Yayın efemeris verileri GRS80 referans elipsoidini kullanan WGS84 sisteminde iken hassas efemeris verileri yine GRS80 referans elipsoidini kullanan ITRF sistemindedir. Ancak bu iki 
sistem arasında belirgin bir fark bulunmadığ 1 bilinmektedir. Ayrıca efemeris verilerinden elde edilen koordinatların doğruluğuna gravite alanının, troposferik ve iyonosferik faktörlerin etki ettiği de göz önünde bulundurulmalıdır. Hassas efemeris ve yayın efemerisi arasındaki farkların az olduğu ve mühendislik çalışmalarının çoğu için yayın efemerisinin yeterli doğruluğu sağlayacağ1 değerlendirilebilir (Hull 1989, Tuşat ve Turgut 2004, Tusat ve Ozyuksel 2018).

Yayın efemerisi ve hassas efemeris karşılaştırıldığında istenen hassasiyet ve efemeris verilerine ulaşmak için geçen zaman belirleyici faktörler olmaktadır. Mühendislik uygulamalarının çoğu için yayın efemerisi gerekli hassasiyeti sağlarken aynı zamanda bu veriye anlık olarak ulaşılabilmektedir. $\mathrm{Bu}$ özellikleri ile hassas efemerise göre kullanımı daha pratiktir. Hassas efemeris verilerine ise yaklaşık bir gün ila iki hafta sonra internet üzerinden ulaş1labilmektedir. Ancak yayın efemerisi verileri ile hassas efemeris verileri arasındaki fark her ne kadar az olsa da yüksek hassasiyet gerektiren jeodezik uygulamalar için hassas efemeris verilerinin kullanılmasının daha doğru bir yaklaşım olacağı söylenebilir.

\section{KAYNAKÇA}

Bidikar, B., Rao, G., S., Ganesh, L., ve Kumar, S., (2014). Satellite clock error and orbital solution error estimation for precise navigation applications. Positioning, 5, 2226.

Hull, W. V., (1989). Geometric geodetic accuracy standards and specifications for using GPS relative positioning techniques. $M D$ : National Geodetic Survey.

IGS, (2017). International GNSS Service. http://www.igs.org/, [Erişim Tarihi; 01.03.2019]

İpek, M., (2017). Satellite Orbit Estimation Using Kalman Filters. Phd Thesis. In Middle East Technical University.

Kahveci, M., ve Yıldız, F., (2009). GPS/GNSS: uydularla konum belirleme sistemleri: teori ve uygulama. Nobel Yayınları, Ankara.

Karaali, C. ve Yıldırım, Ö., (1996). Global Konum Belirleme Sistemi (GPS). Pamukkale Üniversitesi Mühendis. Fakültesi Mühendis. Bilim. Derg., 2(2), 103-108.

Kim, M., ve Kim, J., (2015). A Long-term Analysis of the GPS Broadcast Orbit and Clock Error Variations. Procedia Engineering, 99, 654-658.
Parkinson, B., W., ve Spilker, J.J., (1996). Global positioning system: Theory and applications. American Institute of Aeronautics and Astronautics, 2.

Seeber, G., (1993). Satellite Geodesy: Foundations, Methods and Applications. Walter de Gruyter.

Tuşat, E., Turgut, B., (2004). GPS Efemeris Bilgisinin Göreli Konumlamada Koordinatlara ve Baz Bileşenlerine Etkisi. Selçuk Üniversitesi Mühendislik, Bilim ve Teknoloji Dergisi, 19(1), 65-72.

Tusat, E., Ozyuksel, F., (2018). Comparison of Gps Satellite Coordinates Computed From Broadcast and Igs Final Ephemerides. International Journal of Engineering and Geosciences (IJEG), Vol; 3, Issue 1, pp. 012-019, February, 2018 .

$\mathrm{Xu}$, G., (2016). GPS: theory, algorithms and applications. Springer. 